\title{
A Case Report of Visual Disturbance Caused by Thrombosis of the Superior Sagittal Sinus
}

\author{
Daiki Taniyama ${ }^{1}$, Tsuyoshi Torii ${ }^{*}$, Junichiro Kuga ${ }^{2}$, Yoriko Dodo ${ }^{2}$, Hitomi Tanaka ${ }^{2}$, \\ Yoshimasa Sueda ${ }^{2}$ and Kiyomi Taniyama ${ }^{3}$
}

\begin{abstract}
Departments of ${ }^{1}$ Postgraduate Clinical Education, ${ }^{2}$ Neurology, and ${ }^{3}$ Institute for Clinical Research, National Hospital Organization Kure Medical Center and Chugoku Cancer Center, Kure Japan
\end{abstract}

\begin{abstract}
Superior sagittal sinus thrombosis is a rare condition caused by several diseases including malignancy. Major symptoms include headache, seizure, and motor weakness. Ocular sign is a minor symptom. The present case had visual disturbance caused by thrombosis of the superior sagittal sinus, which is an extremely rare case that was treated successfully by our team.
\end{abstract}

Keywords: Cerebral venous thrombosis, Optic papilla, Congestion, Lung, Hypercoagulopathy, Squamous cell carcinoma.

\section{INTRODUCTION}

Superior sagittal sinus thrombosis is rare and accounts for only one in 100 thousand population per year [1]. Risk factors for cerebral venous thrombosis (CVT) and some characteristic symptoms exist with this thrombosis are shown in Tables 1 and 2 [1, 2-6]. We treated a case with superior sagittal sinus thrombosis with only visual disturbance.

Table 1: The Risk Factors of Cerebral Venous Thrombosis

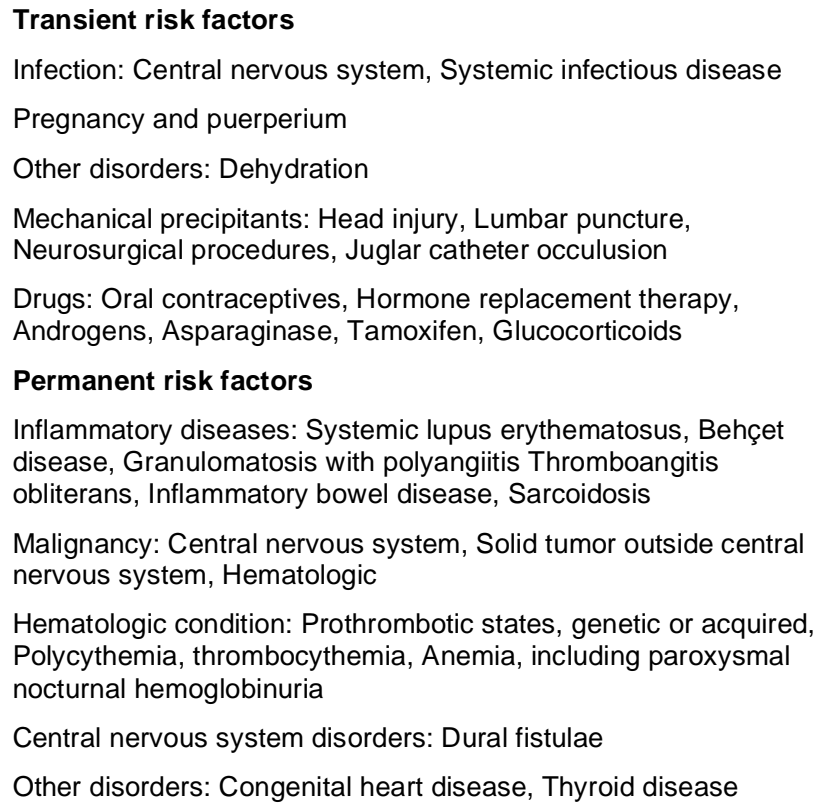

*Address correspondence to this author at the Department of Neurology, National Hospital Organization Kure Medical Center and Chugoku Cancer Center, 3-1 Aoyama-cho, Kure 737-0023, Japan; Tel: +81-823-22-3111; Fax: +81-823-22-0478; E-mail: toriit@kure-nh.go.jp

\section{Table 2: Symptoms of Cerebral Venous Thrombosis}

Headache (89\%): Usually the first symptom. Worsens with valsalva maneuvers and with recumbency. Onset is usually gradual, but some have sudden onset similar to subarachnoid hemorrhage.

Seizure (39\%): Status epilepticus is also frequent.

Motor weakness (37\%): Monoparesis or hemiparesis, sometimes bilateral, is the most frequent. Aphasia, sensory deficits and visual disturbance are less common.

Encephalopathy; Disturbance of consciousness and cognitive dysfunction can be present in severe cases.

Ocular signs; Such as orbital pain, chemosis, proptosis, and oculomotor palsies.

\section{CASE}

A 65-year-old Japanese man complained of visual disturbance lasting for about 30 seconds upon arising a few times a day for one month. He was a heavy drinker and smoker for 45 years with a medical history of hypertension and diabetes mellitus. He was referred to ophthalmology in our hospital and was admitted to the neurology service. On the same day, an optical examination revealed strong congestion of his optic papilla and low vision (rt: 20/250 vision; It: 20/100 vision) (Figure 1). Although the laboratory test results from peripheral blood showed no abnormality of platelets count, dehydration, or prothrombotic condition (Table 3), computed tomography (CT) and magnetic resonance imaging (MRI) examinations identified thrombus of the superior sagittal sinus (Figures 2, 3). Thereafter, anticoagulation therapy was implemented. CT also revealed a right lung mass with no metastasis. The tumor was a squamous cell carcinoma (T1N0M0, stage IIA), which was surgically resected two months after admission (Figure 4). CVT diminished and 


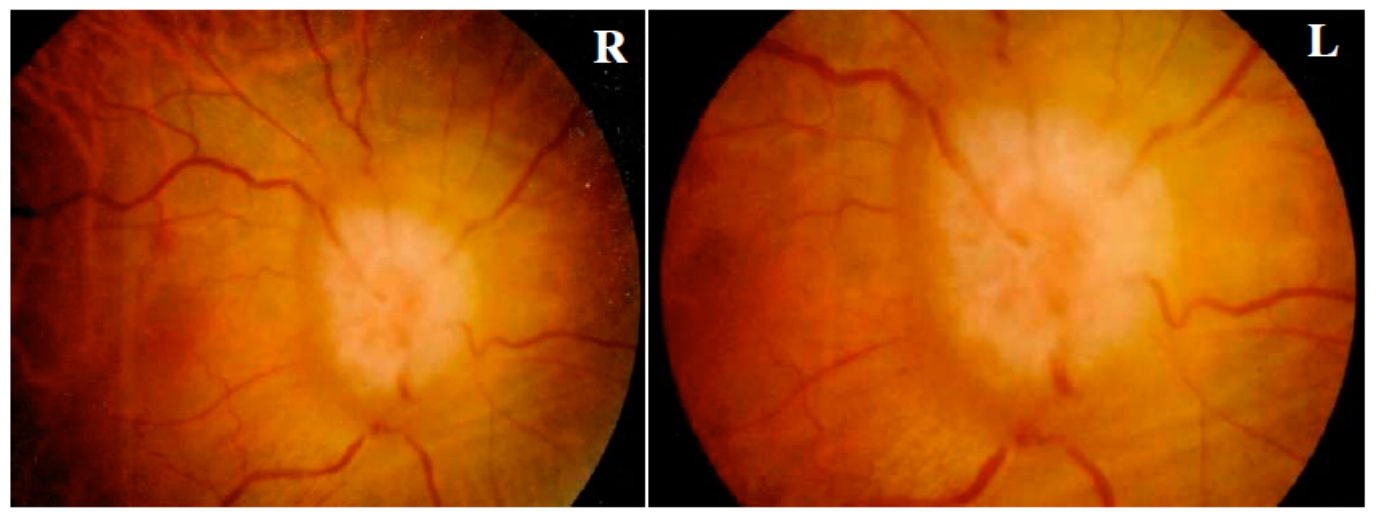

Figure 1: Ophthalmological findings indicating strongly congested optic papilla of the patient. (Abbreviations: R-right; L-left).

Table 3: Laboratory Findings

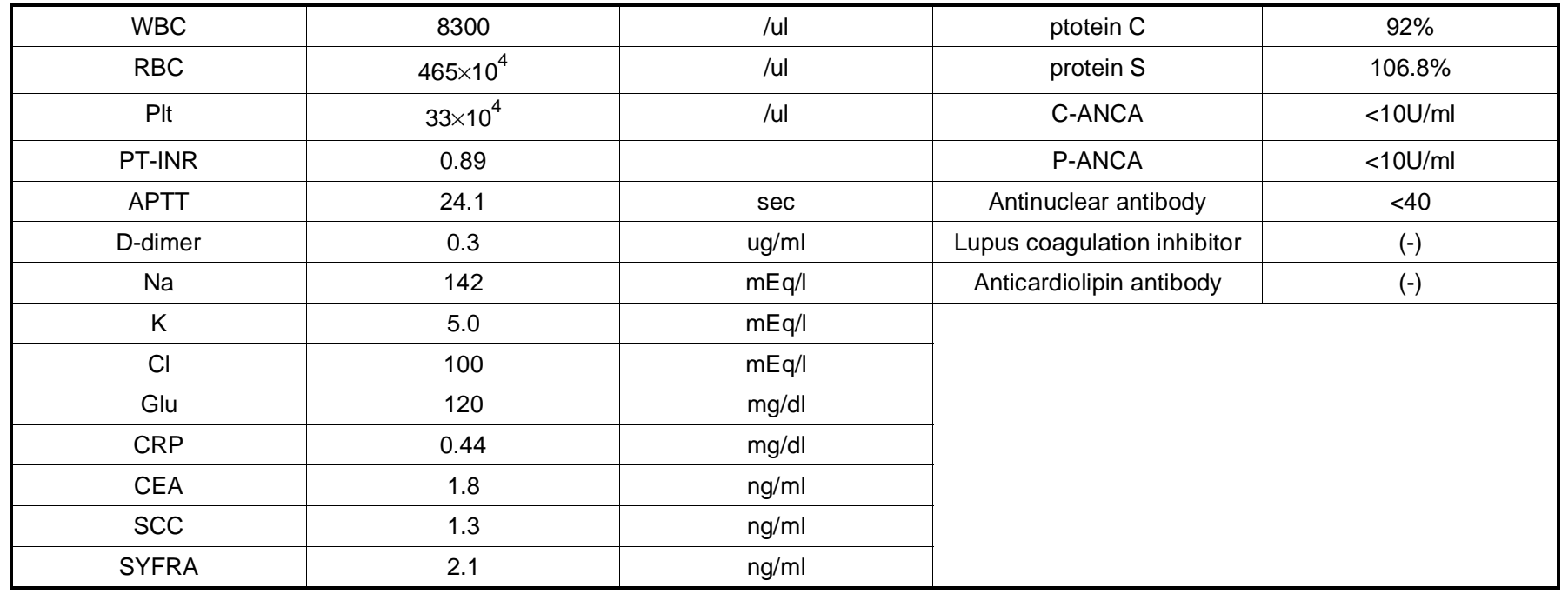

*Data shows no abnormity.

No prothrombotic condition is found.

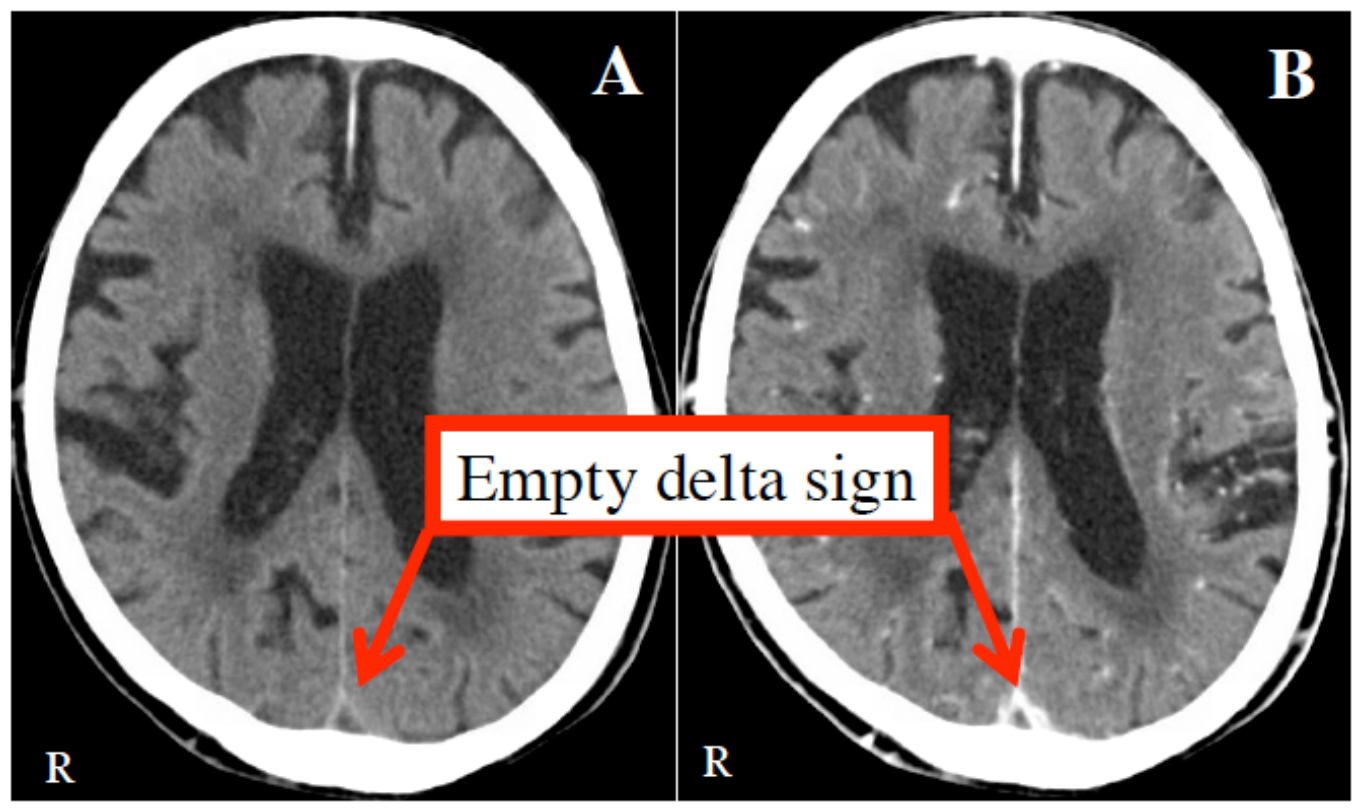

Figure 2: Computed tomography (CT) examination showing an empty delta sign, which is the direct sign of thrombosis in the posterior part of the superior sagittal sinus (A. non-contrast enhanced; B. contrast enhanced). 


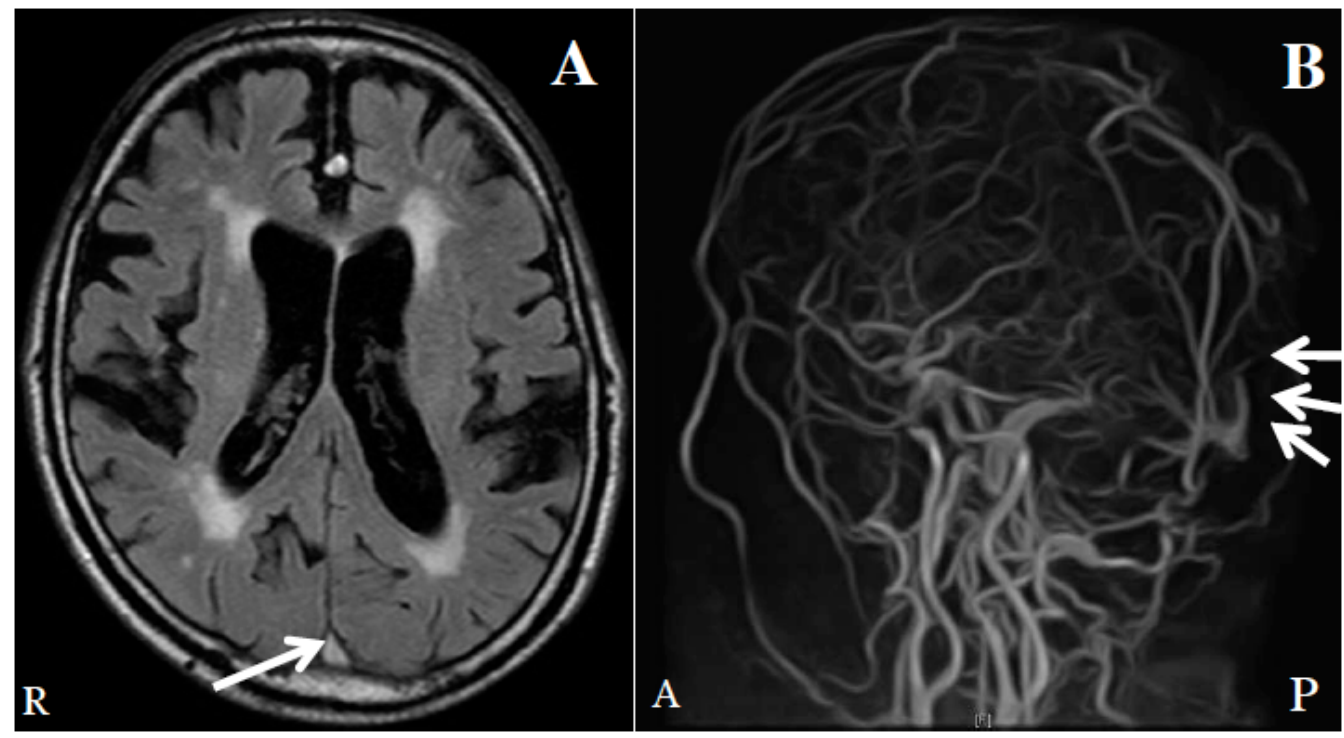

Figure 3: Magnetic resonance imaging (MRI) examination showing a hyperdensity sign (A. arrow, MRI FLAIR) and an absence of bloody flow (B. arrows, MRI venography) in the superior sagittal sinus. (Abbreviations: R-right; A-anterior; P-posterior).
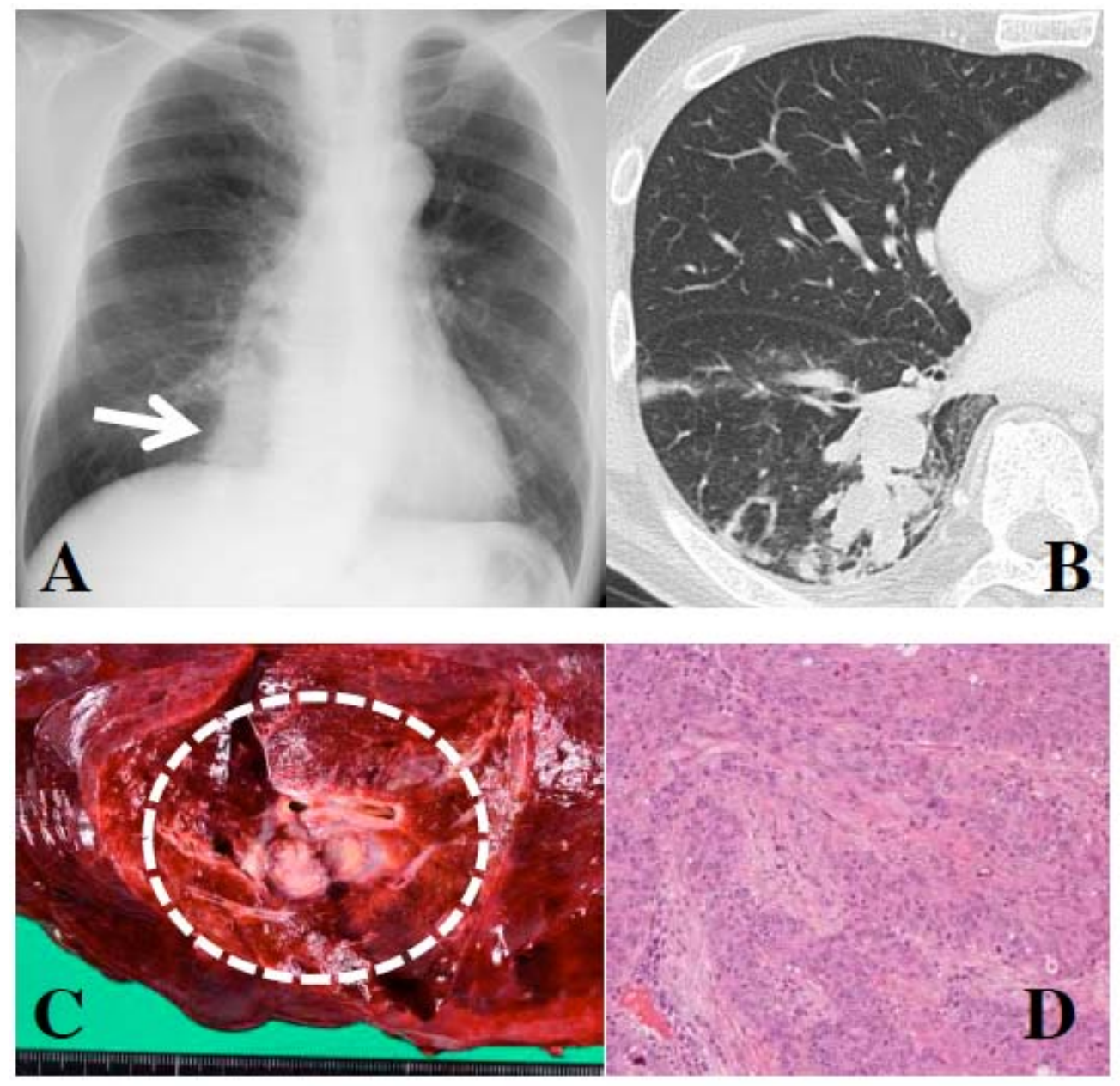

Resected tissues

Figure 4: Chest X-ray (A. arrow) and CT (B.) examinations showing a space occupying legion in the lower portion of right lung. Resected right lung showed a squamous cell carcinoma of T2bN0M0 Stage II A (C. circle) and in microscopy (D. Hematoxylin and Eosin staining, objective 20X). 


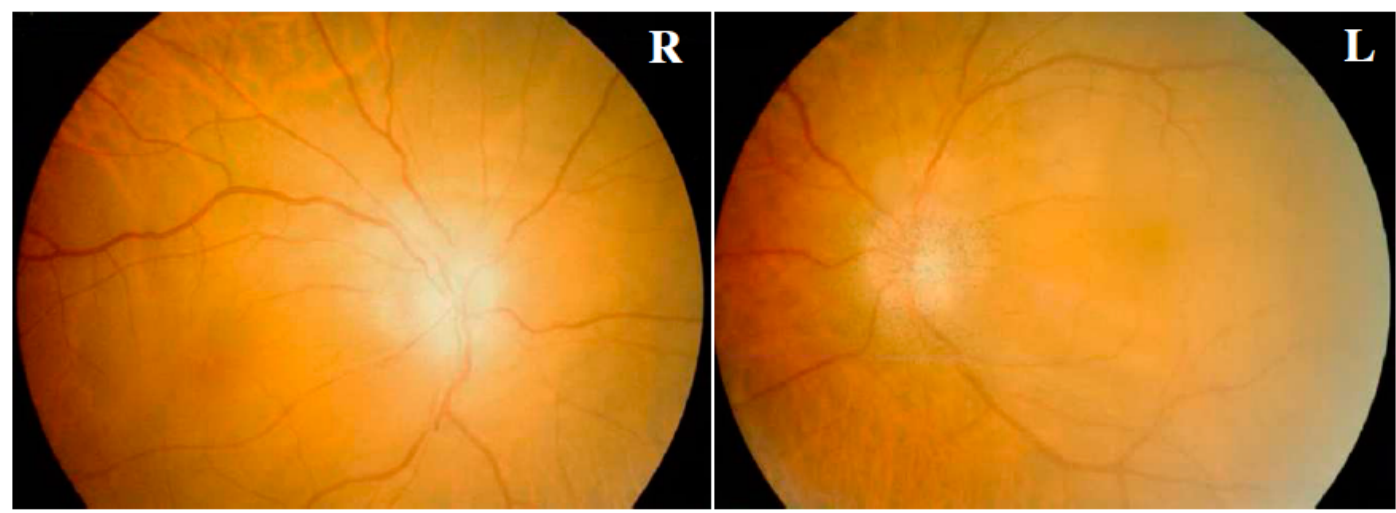

Figure 5: Ophthalmological findings indicating no congestion of the optic papilla one year after the operation.

congestion of the optic papilla improved gradually, and showed no congestion one year after the operation (Figure 5).

\section{DISCUSSION}

In the present case, elevation of cerebrospinal pressure was determined to cause the visual disturbance and congested papilla. Diseases with an increase of cerebrospinal pressure are shown in Table 4 [2]. Thrombosis in this location is quite rare [1]. The risk factors of CVT have been classified into transient or permanent as shown in Table 1. The most frequent is a prothrombotic condition and highly frequent factors include oral contraceptives, pregnancy, malignancy, infection, head injury, and mechanical precipitants [2].

\section{Table 4: Causes of the Increased Internal Pressure}

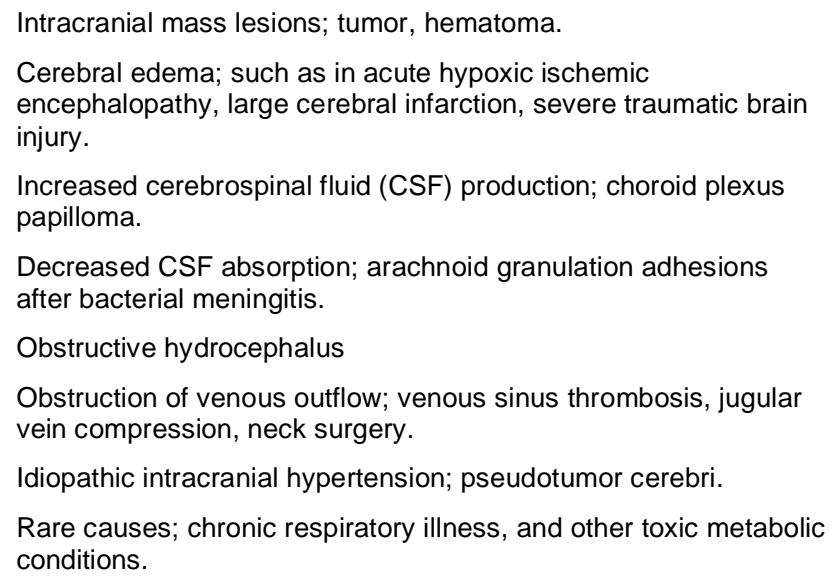

Decreased CSF absorption; arachnoid granulation adhesions after bacterial meningitis.

Obstructive hydrocephalus

Obstruction of venous outflow; venous sinus thrombosis, jugular vein compression, neck surgery.

Idiopathic intracranial hypertension; pseudotumor cerebri.

Rare causes; chronic respiratory illness, and other toxic metabolic conditions.

Initially, we considered that the patient might have some kind of occult malignancy or infection with the present and past history. We then detected a lung carcinoma stage IIA, and the surgical resection coupled with anticoagulant therapy lead to diminishing of CVT and congestion of optic papilla.
Among characteristic symptoms with CVT, as shown in Table 2, headache and convulsion are relatively common [2-6]. In the present case, however, the patient complained of only visual disturbance due to the congested optic papilla. We considered this congestion being caused by an evacuation disturbance of cerebrospinal fluid due to the thrombosis in the superior sagittal sinus, which was related to the accelerated coagulopathy due to the lung carcinoma.

Malignancy has been reported as a major risk factor for CVT. According to the report from the International Study on Cerebral Vein and Dural Sinus Thrombosis (ISCVT), $7.4 \%$ of CVT cases were associated with cancer, and the researchers noted greater frequency in patients with hematologic malignancies [7]. Potential mechanisms for an association of cancer with CVT include direct tumor compression of vessels, tumor invasion of cerebral sinuses [8-10], or the hypercoagulable state associated with cancer [11]. Chemotherapeutic and hormonal agents used for cancer treatment may also play a role [12]. Some reports suggested that many tumors associated with thrombotic complications were mucin-secreting adenocarcinomas of the gastrointestinal tract, ovary, prostate, and lung [13-16]. Mucin produced by adenocarcinomas may trigger this thrombosis by reacting with leukocyte and platelet selectins, which results in the production of platelet-rich microthrombi [17-19]. However, many nonmucin-producing tumors were also associated with hypercoagulability [20,21].

In the present case, we considered the possibility of an accelerated coagulopathy due to the lung carcinoma as the cause of thrombosis in the superior sagittal sinus among all possibilities listed in Table 1, even though no findings indicated hypercoagulability or microthrombosis of the superior sagittal sinus due to lung carcinoma metastasis. Among 624 patients with 
CVT in the ISCVT study, 41 had recurrent thrombotic events, $17(41.5 \%)$ of which had been treated with anticoagulants. This result might indicate that anticoagulants are not enough to treat CVT in some cases, and the surgical resection of lung carcinoma in addition to the coagulants therapy would be effective for the complete disappearance of CVT in the present case.

In conclusion, we have succeeded in treating a patient with visual disturbance that was caused by thrombosis in the superior sagittal sinus. This experience would be beneficial for persons that have visual disturbance of unknown etiology.

\section{REFERENCES}

[1] Saposnik G, Barinagarrementeria F, Brown RD Jr, et al. Diagnosis and management of cerebral venous thrombosis: a statement for healthcare professionals from the American Heart Association/American Stroke Association. Stroke 2011; 42: 1158. http://dx.doi.org/10.1161/STR.0b013e31820a8364

[2] Ferro JM, Canhão P, Stam J, et al. Prognosis of cerebral vein and dural sinus thrombosis: results of the International Study on Cerebral Vein and Dural Sinus Thrombosis (ISCVT). Stroke 2004; 35: 664 http://dx.doi.org/10.1161/01.STR.0000117571.76197.26

[3] Ferro JM, Canhão P, Bousser MG, et al. Early seizures in cerebral vein and dural sinus thrombosis: risk factors and role of antiepileptics. Stroke 2008; 39: 1152. http://dx.doi.org/10.1161/STROKEAHA.107.487363

[4] Jacobs K, Moulin T, Bogousslavsky J, et al. The stroke syndrome of cortical vein thrombosis. Neurology 1996; 47: 376.

http://dx.doi.org/10.1212/WNL.47.2.376

[5] Ahn TB, Roh JK. A case of cortical vein thrombosis with the cord sign. Arch Neurol 2003; 60: 1314. http://dx.doi.org/10.1001/archneur.60.9.1314

[6] Cakmak S, Hermier M, Montavont A, et al. T2*-weighted MRI in cortical venous thrombosis. Neurology 2004; 63: 1698. http://dx.doi.org/10.1212/01.WNL.0000138502.59539.CB

[7] Ferro JM, Canhão $P$, Stam J, Bousser MG, Barinagarrementeria F; ISCVT Investigators. Prognosis of cerebral vein and dural sinus thrombosis: results of the International Study on Cerebral Vein and Dural Sinus Thrombosis (ISCVT). Stroke 2004; 35: 664-670. http://dx.doi.org/10.1161/01.STR.0000117571.76197.26
[8]

Kim AW, Trobe JD. Syndrome simulating pseudotumor cerebri caused by partial transverse venous sinus obstruction in metastatic prostate cancer. Am J Ophthalmol 2000; 129: 254.

\section{http://dx.doi.org/10.1016/S0002-9394(99)00326-8}

[9] Meininger V, James JM, Rio B, Zittoun R. Dural venous sinus occlusions in hemopathies [in French]. Rev Neurol (Paris). 1985; $141: 228$.

[10] Raizer JJ, DeAngelis LM. Cerebral sinus thrombosis diagnosed by MRI and MR venography in cancer patients. Neurology 2000; 54: 1222. http://dx.doi.org/10.1212/WNL.54.6.1222

[11] Rogers LR. Cerebrovascular complications in patients with cancer. Semin Neurol 2004; 24: 453. http://dx.doi.org/10.1055/s-2004-861539

[12] Gustavo S, Fernando B, Robert D, et al. AHA/ASA Scientific Statement,Diagnosis and Management of Cerebral Venous Thrombosis. Stroke 2011; 42: 1158. http://dx.doi.org/10.1161/STR.0b013e31820a8364

[13] Amico L, Caplan LR, Thomas C. Cerebrovascular complications of mucinous cancers. Neurology 1989; 39: 522.

http://dx.doi.org/10.1212/WNL.39.4.522

[14] Pinzon R, Drewinko B, Trujillo JM, et al. Pancreatic carcinoma and Trousseau's syndrome: experience at a large cancer center. J Clin Oncol 1986; 4: 509.

[15] Sproul EE. Carcinoma and venous thrombosis: The frequency of association of carcinoma in the body or tail of the pancreas with multiple venous thrombosis. Am $\mathrm{J}$ Cancer 1938; 34: 566

[16] Rickles FR, Edwards RL. Activation of blood coagulation in cancer: Trousseau's syndrome revisited. Blood 1983; 62: 14.

[17] Wahrenbrock M, Borsig L, Le D, Varki N, Varki A. Selectinmucin interactions as a probable molecular explanation for the association of Trousseau syndrome with mucinous adenocarcinomas. J Clin Invest 2003; 112: 853.

[18] Varki A. Trousseau's syndrome: multiple definitions and multiple mechanisms. Blood 2007; 110: 1723. http://dx.doi.org/10.1182/blood-2006-10-053736

[19] Shao B, Wahrenbrock MG, Yao L, et al. Carcinoma mucins trigger reciprocal activation of platelets and neutrophils in a murine model of Trousseau syndrome. Blood 2011; 118: 4015.

http://dx.doi.org/10.1182/blood-2011-07-368514

[20] Blom JW, Osanto S, Rosendaal FR. The risk of a venous thrombotic event in lung cancer patients: higher risk for adenocarcinoma than squamous cell carcinoma. J Thromb Haemost 2004; 2: 1760 http://dx.doi.org/10.1111/j.1538-7836.2004.00928.x

[21] Chew HK, Davies AM, Wun T, et al. The incidence of venous thromboembolism among patients with primary lung cancer. J Thromb Haemost 2008; 6: 601 .

http://dx.doi.org/10.1111/j.1538-7836.2008.02908.x

http://dx.doi.org/10.6000/1927-7229.2014.03.01.7

(C) 2014 Taniyama et al.; Licensee Lifescience Global.

This is an open access article licensed under the terms of the Creative Commons Attribution Non-Commercial License (http://creativecommons.org/licenses/by-nc/3.0/) which permits unrestricted, non-commercial use, distribution and reproduction in any medium, provided the work is properly cited. 